Swarthmore College

Works

$12-31-2018$

\title{
Mechanism For Copper(II)-Mediated Disaggregation Of A Porphyrin J-Aggregate
}

\author{
M. Trapani \\ I. G. Occhiuto \\ R. Zagami \\ G. De Luca \\ M. A. Castriciano
}

See next page for additional authors

Follow this and additional works at: https://works.swarthmore.edu/fac-chemistry

Part of the Inorganic Chemistry Commons

Let us know how access to these works benefits you

\section{Recommended Citation}

M. Trapani, I. G. Occhiuto, R. Zagami, G. De Luca, M. A. Castriciano, A. Romeo, L. M. Scolaro, and Robert F. Pasternack. (2018). "Mechanism For Copper(II)-Mediated Disaggregation Of A Porphyrin J-Aggregate". ACS Omega. Volume 3, Issue 12. 18843-18848. DOI: 10.1021/acsomega.8b02913 https://works.swarthmore.edu/fac-chemistry/231

This work is brought to you for free by Swarthmore College Libraries' Works. It has been accepted for inclusion in Chemistry \& Biochemistry Faculty Works by an authorized administrator of Works. For more information, please contact myworks@swarthmore.edu. 


\section{Authors}

M. Trapani, I. G. Occhiuto, R. Zagami, G. De Luca, M. A. Castriciano, A. Romeo, L. M. Scolaro, and Robert F. Pasternack 


\title{
Mechanism for Copper(II)-Mediated Disaggregation of a Porphyrin J-Aggregate
}

\author{
Mariachiara Trapani, ${ }^{\dagger}$ Ilaria G. Occhiuto, ${ }^{\ddagger}$ Roberto Zagami, ${ }^{\dagger}$ Giovanna De Luca, ${ }^{\ddagger}$,

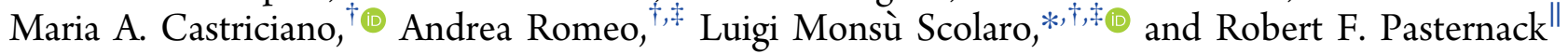

${ }^{\dagger}$ CNR-ISMN, Istituto per lo Studio dei Materiali Nanostrutturati, c/o Dipartimento di Scienze Chimiche, Biologiche, Farmaceutiche ad Ambientali, 98166 V.le F. Stagno D’Alcontres 31, Messina, Italy

${ }^{\ddagger}$ Dipartimento di Scienze Chimiche, Biologiche, Farmaceutiche ad Ambientali, and C.I.R.C.M.S.B., University of Messina, V.le F. Stagno D’Alcontres 31, Vill. S. Agata, 98166 Messina, Italy

${ }^{\S}$ CNR-IPCB, Istituto dei Polimeri, Compositi e Biomateriali, P.le Enrico Fermi 1, 80055 Portici, Naples, Italy

"Department of Chemistry \& Biochemistry, Swarthmore College, 500 College Avenue, Swarthmore, Pennsylvania 19081, United States

Supporting Information

ABSTRACT: J-aggregates of anionic meso-tetrakis(4sulfonatophenyl)porphyrin form at intermediate $\mathrm{pH}(2.3-$ 3.1) in the presence of $\mathrm{NiSO}_{4}$ or $\mathrm{ZnSO}_{4}$ (ionic strength, I.S. = 3.2 M). These aggregates convert to monomeric porphyrin units via metallation with copper(II) ions. The kinetics for the disassembly process, as monitored by UV/vis spectroscopy, exhibits zeroth-order behavior. The observed zeroth-order rate constants show a two-term dependence on copper(II) ion concentrations: linear and second order. Also observed is an inverse dependence on hydrogen ion concentration. Activation parameters have been determined for the disassembly process leading to $\Delta H^{\neq}=(+163 \pm 15) \mathrm{kJ} \cdot \mathrm{mol}^{-1}$ and $\Delta S^{\neq}=$

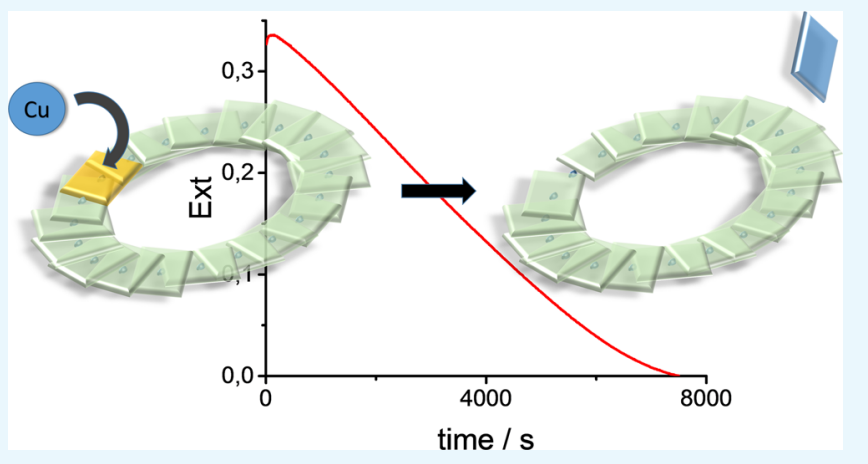
$(+136 \pm 11) \mathrm{J} \cdot \mathrm{K}^{-1}$. A mechanism is proposed in which copper(II) cation is in pre-equilibrium with a reactive site at the rim of the J-aggregate. An intermediate copper species is thus formed that eventually leads to the final metallated porphyrin either through an assisted attack of a second metal ion or through a direct insertion of the metal cation into the macrocycle core.

\section{INTRODUCTION}

Kinetics and mechanisms for metal ion coordination and the removal from a number of porphyrins in aqueous and nonaqueous media have been extensively investigated. ${ }^{1}$ The reactivity in a variety of confined microenvironments, such as micelles $^{2}$ and microemulsions, ${ }^{3}$ or even nucleic acids or proteins ${ }^{4}$ has been explored. On the contrary, the reactivity of porphyrin homoaggregates with metal ions has been the subject of very few studies.

Many water-soluble porphyrins have been shown to aggregate under appropriate conditions of concentration, $\mathrm{pH}$, and ionic strength. ${ }^{5-10}$ The study of such species is facilitated by the impact of aggregation on their basic physical-chemical properties. For example, porphyrin electronic absorption is affected by aggregation leading to blue-shifted or red-shifted bands depending on whether the chromophores interact in a face-to-face (H-dimers) or in a side-by-side geometry (Jdimer), respectively. ${ }^{11-14}$ Extended J-aggregates of porphyrins are of particular interest because of their intriguing optical and electronic properties, such as line narrowing of the absorption bands, resonance light scattering (RLS), enhanced Raman scattering, nonlinear optical effects, and photoconductivity. ${ }^{15-22}$ Water soluble anionic meso-tetrakis(4sulfonatophenyl)porphyrin $\left(\mathrm{TPPS}_{4}\right)$ in its diacid form is able to self-assemble through an extensive network of hydrogen bonding, electrostatic, and hydrophobic interactions ${ }^{23-26}$ (Scheme 1). Depending on experimental conditions and protocol of preparation, these J-aggregates exhibit a variety of different morphologies such as nanoribbons, nanosheets, and hollow nanotubes or fractal structures. ${ }^{24,26-30}$ The kinetics of growth of these supramolecular systems depends on the concentration of the porphyrin and medium properties such as $\mathrm{pH}$, ionic strength, the presence of some cationic species, and temperature. ${ }^{7,25,31-36}$ Their kinetics of formation has been described using models that begin with a nucleation step followed by autocatalytic growth of the assembly. ${ }^{13,37}$ Despite many reports dealing with the kinetics of assembly formation, relatively few studies have focused on the disassembly

Received: October 23, 2018

Accepted: December 19, 2018

Published: December 31, 2018 
Scheme 1. Molecular Structure of Diacid TPPS 4 and Schematic Representation of a J-Aggregate. When Part of Nanotubes, These Basic Structures Fold and Roll Up

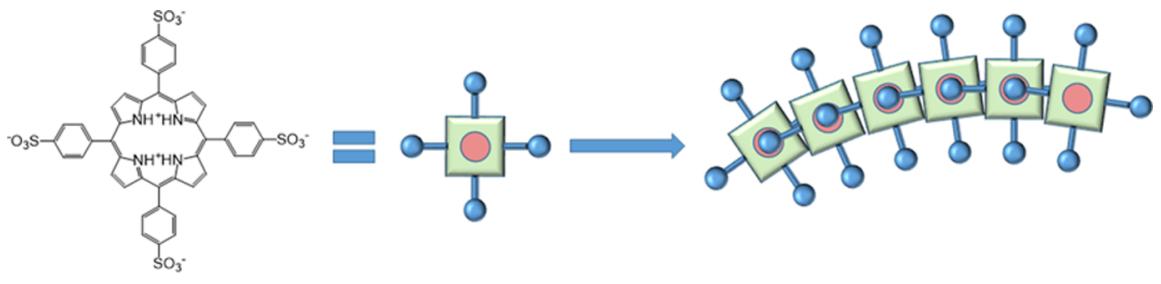

$\mathrm{TPPS}_{4}$

J-aggregate

process. $^{38-44}$ Quite recently, we have shown that J-aggregates of $\mathrm{TPPS}_{4}$ can be restored to the monomeric form through coordination of copper(II) ions into the porphyrin. The insertion of this metal ion into the porphyrin core leads to disruption of the nanoassemblies because it prevents any of the possible stabilizing interactions between adjacent porphyrins.

Reactions of metal ions with porphyrins have been investigated largely under pseudo-first-order conditions (i.e., a large excess of metal ions with respect to porphyrin), and the derived rate laws are in most cases first order both in porphyrin and in metal ion concentration. Furthermore, the rate law may contain a term or terms depending on the specific counteranion and proton concentration. ${ }^{40}$ As previously shown, $\mathrm{TPPS}_{4}$ J-aggregates react with copper(II) in a manner strongly dependent on the details of the mixing protocol of the reagents. The combined experimental evidence supports an attack by the metal ion at the external rims of the supramolecular assemblies. ${ }^{40}$ Because of the importance of disaggregation to various applications, we decided to extend our earlier study on the factors affecting the rate of this process. To permit as a wide range of conditions as possible, we chose to work under relatively mild acid conditions $(\mathrm{pH}$ 2.3-3.1) and to promote aggregation through the addition of metal salts (ionic strength, I.S. $=3.2 \mathrm{M}$ ). To the best of our knowledge, this is the first detailed study on the mechanism of metal ion insertion into an already highly aggregated porphyrin system.

\section{RESULTS AND DISCUSSION}

The formation of J-aggregates from the porphyrin diacid $\left(\mathrm{H}_{4} \mathrm{TPPS}_{4}\right)$ can be triggered by using low $\mathrm{pH}$ conditions ${ }^{7,23}$ or, at intermediate $\mathrm{pH}$, by providing a high ionic strength environment. $^{24,30,32}$ In a micromolar concentration range at $\mathrm{pH}$ values between 2.3 and 3.1, the TPPS 4 porphyrin is in its non-J-aggregated diacid form $\left(\mathrm{p} K_{\mathrm{a}}=4.9\right)$. An increase in the ionic strength of the aqueous solution leads to the formation of J-aggregates arising from the screening of the electrostatic repulsions between interacting porphyrin units. In our experiments, $\mathrm{Ni}(\mathrm{II})$ or $\mathrm{Zn}$ (II) sulfate was used to provide the desired fixed ionic strength $($ I.S. $=3.2 \mathrm{M})$. These two dblock metal ions were chosen based on their similarity to copper(II) except for their limited reactivity under acidic conditions to form the corresponding metalloporphyrin complexes. ${ }^{45}$ Zinc(II) rapidly inserts into the porphyrin, but the corresponding metal complex is labile in our $\mathrm{pH}$ range, leading to rapid demetallation, or exchange with copper(II) ions. ${ }^{46} \mathrm{Ni}$ (II) is significantly less reactive than either zinc(II) or copper(II). ${ }^{47}$ It was chosen for the experiments reported in the main text; results for the more labile zinc(II), which are used for comparison and follow similar trends, are collected in
Supporting Information. Figure 1A shows the typical UV/vis absorption spectral changes for the formation of J-aggregates in
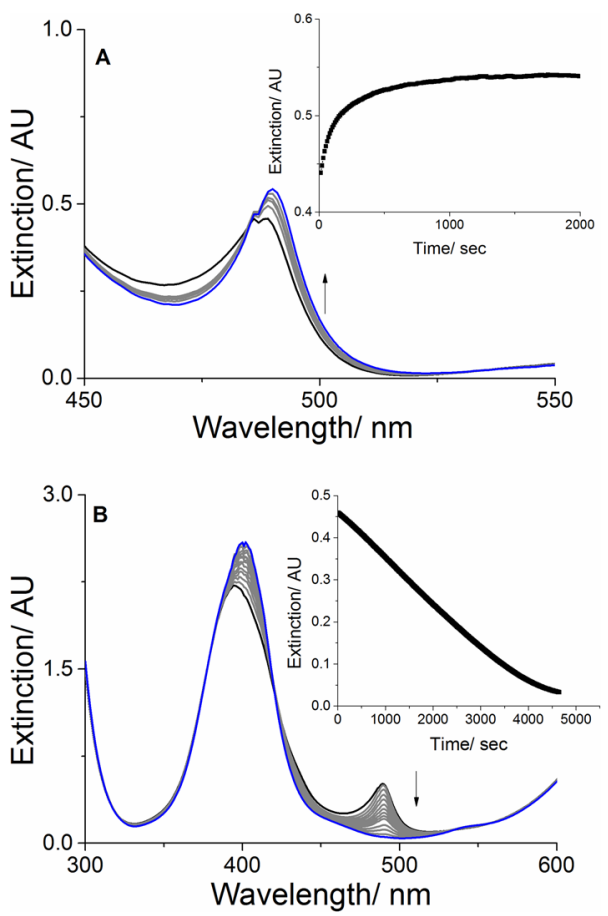

Figure 1. (A) $\mathrm{UV} /$ vis spectral changes for the formation of $\mathrm{J}$ aggregates of the porphyrin $\mathrm{TPPS}_{4}$, according to a porphyrin last mixing protocol, spectra have been collected with a scanning time of $10 \mathrm{~s}\left(\left[\mathrm{TPPS}_{4}\right]=3 \mu \mathrm{M},\left[\mathrm{H}_{2} \mathrm{SO}_{4}\right]=0.05 \mathrm{M}\right.$, I.S. $\left.=3.2 \mathrm{M}, \mathrm{T}=298 \mathrm{~K}\right)$. The inset shows the corresponding kinetic profile at $490 \mathrm{~nm}$. (B) UV/ vis spectral changes for the disassembly process of equilibrated $\mathrm{TPPS}_{4}$ $\mathrm{J}$-aggregates upon addition of $\mathrm{CuSO}_{4}$, spectra have been collected with a scanning time of $10 \mathrm{~s}\left(\left[\mathrm{TPPS}_{4}\right]=3 \mu \mathrm{M},\left[\mathrm{H}_{2} \mathrm{SO}_{4}\right]=0.05 \mathrm{M}\right.$, $\left[\mathrm{CuSO}_{4}\right]=0.3 \mathrm{M}$, I.S. $\left.=3.2 \mathrm{M}\left(\mathrm{NiSO}_{4}\right), T=298 \mathrm{~K}\right)$. The inset shows the corresponding kinetic profile at $490 \mathrm{~nm}$. The notch detectable at $486 \mathrm{~nm}$ is an experimental artifact because of the deuterium emission spectra from the instrument lamp and an imperfect baseline correction.

the presence of $\mathrm{NiSO}_{4}$. Upon mixing the reagents, the formation of the nanoassemblies can be monitored by the rapid appearance and increase in intensity of a band at $490 \mathrm{~nm}$, that is, the spectroscopic signature of J-aggregated TPPS 4 . The kinetic traces for this process follow a stretched exponential behavior that is characteristic for the "porphyrin last" mixing protocol described in previous investigations. When copper(II) sulfate is added to an equilibrated solution of J-aggregates, the J-band at $490 \mathrm{~nm}$ decreases linearly with time, that is, zeroorder kinetics are observed (Figure $1 \mathrm{~B}$ ). When $\mathrm{ZnSO}_{4}$ is used 
as a supporting electrolyte, a two-component B-band region grows in 412 and $405 \mathrm{~nm}$ because of the formation of the final reaction product, $\mathrm{CuTPPS}_{4}$ (data not shown). ${ }^{40}$ These spectral features have been identified as arising from the monomer/ dimer equilibrium of $\mathrm{CuTPPS}_{4}$ previously studied with very fast relaxation methods. ${ }^{48}$ In the presence of $\mathrm{NiSO}_{4}$ as a supporting electrolyte, as is the case of the reported spectra, the ${ }^{3} \mathrm{~A}_{2 \mathrm{~g}} \rightarrow{ }^{3} \mathrm{~T}_{1 \mathrm{~g}}(\mathrm{P})$ transition around $400 \mathrm{~nm}$ due to $\left[\mathrm{Ni}\left(\mathrm{H}_{2} \mathrm{O}\right)_{6}\right]^{2+}$ masks these spectral changes. ${ }^{49}$

To investigate the dependence of the rate for the disassembly process on experimental parameters, we prepared samples of J-aggregates (according to the above protocol) and induced their deaggregation by adding $\mathrm{CuSO}_{4}$. From the slope of the zeroth-order kinetic traces, we calculated the values for the rate constants, $k_{0}\left(\mathrm{M} \cdot \mathrm{s}^{-1}\right)$. Their values together with the corresponding estimated errors are collected in Tables SI1SI3 for the various experiments. Consistent with zero-order kinetics, the observed rate constants $k_{0}$ do not exhibit any dependence on the initial porphyrin concentration (Figure SI1). At constant $\mathrm{pH}$, the rate constants $k_{0}$ shows a nonlinear dependence on $\left[\mathrm{Cu}^{2+}\right]$ (Figure 2 and Figure SI2). These data

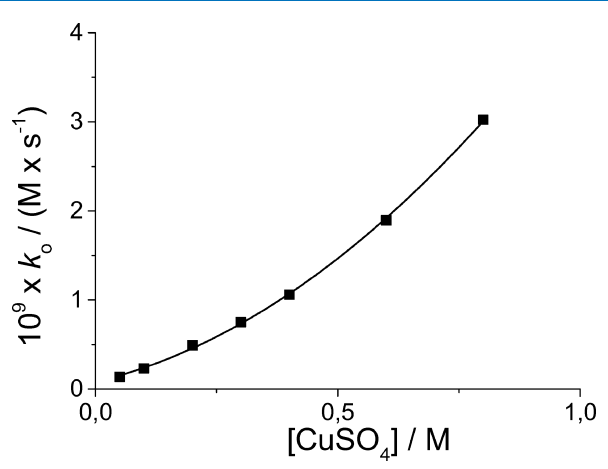

Figure 2. Plot of the observed zeroth-order rate constant $k_{0}$ vs $\left[\mathrm{Cu}^{2+}\right]$ at constant $\mathrm{pH}\left(\left[\mathrm{TPPS}_{4}\right]=3 \mu \mathrm{M},\left[\mathrm{H}_{2} \mathrm{SO}_{4}\right]=0.0016 \mathrm{M}\right.$, I.S. $=3.2 \mathrm{M}$ $\left.\left(\mathrm{NiSO}_{4}\right), T=298 \mathrm{~K}\right)$.

can be conveniently fitted by a second-order polynomial function of the form: $k_{0}=(7.96 \pm 2.52) \times 10^{-11} \mathrm{M} \cdot \mathrm{s}^{-1}+(1.29$ $\pm 0.15) \times 10^{-9} \mathrm{~s}^{-1}\left[\mathrm{Cu}^{2+}\right]+(2.96 \pm 0.02) \times 10^{-9} \mathrm{M}^{-1} \cdot \mathrm{s}^{-1}$ $\left[\mathrm{Cu}^{2+}\right]^{2}\left(\right.$ at $\left.\mathrm{pH}=2.56, R^{2}=0.99939\right)$. This behavior is different from that previously reported for this system for $\left[\mathrm{Cu}^{2+}\right]<0.3 \mathrm{M}^{40}$ suggesting different reaction pathways leading to the final reaction products in different regimes of metal ion concentration.

At fixed $\left[\mathrm{Cu}^{2+}\right]$, the rate constant shows a linear dependence on the inverse hydrogen ion concentration (Figure 3 and Figure SI3), giving a slope of $(6.83 \pm 0.15) \times 10^{-12} \mathrm{M}^{2} \cdot \mathrm{s}^{-1}$. Such a dependence has been observed previously for the reaction with copper(II) of the water-soluble 2,4-disulfonated deuteroporphyrin dimethyl ester in acidic and neutral solutions. ${ }^{50}$ We note that the range of $\mathrm{pH}$ accessible in the experiments is limited by the acid stability of the J-aggregates at $\mathrm{pH}<2.3$.

The rate law for the disassembly process is derived from the mechanism shown in Scheme 2 and is zero order because it is independent on the aggregate or the porphyrin concentration

$$
\begin{aligned}
& \text { rate }=-\mathrm{d}[\mathrm{Agg}] / \mathrm{d} t=k_{1} K\left(\left[\mathrm{Cu}^{2+}\right] /\left[\mathrm{H}^{+}\right]\right) \\
& \quad+k_{2} K\left(\left[\mathrm{Cu}^{2+}\right]^{2} /\left[\mathrm{H}^{+}\right]\right)=k_{0}
\end{aligned}
$$

where the meaning of $k_{0}, k_{1}, k_{2}$, and $K$ is discussed below.

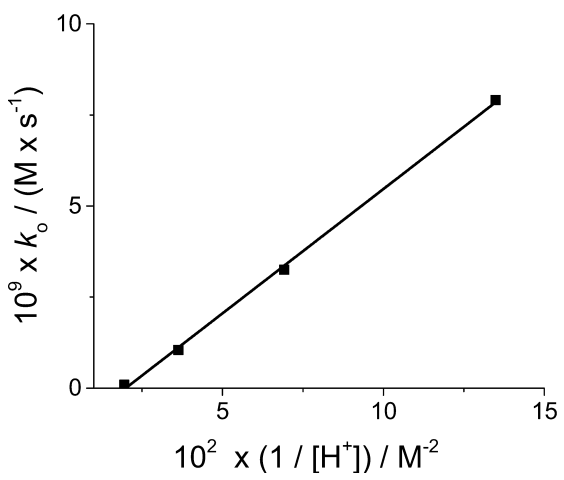

Figure 3. Plot of the observed zeroth-order rate constant $k_{0}$ vs $1 /\left[\mathrm{H}^{+}\right]$ $\left(\left[\mathrm{TPPS}_{4}\right]=3 \mu \mathrm{M},\left[\mathrm{Cu}^{2+}\right]=0.4 \mathrm{M}\right.$, I.S. $\left.=3.2 \mathrm{M}\left(\mathrm{NiSO}_{4}\right), T=298 \mathrm{~K}\right)$.

Scheme 2. Mechanism Proposed for the Disassembly Process of TPPS $_{4}$ J-Aggregates by Copper(II) Metal Ions

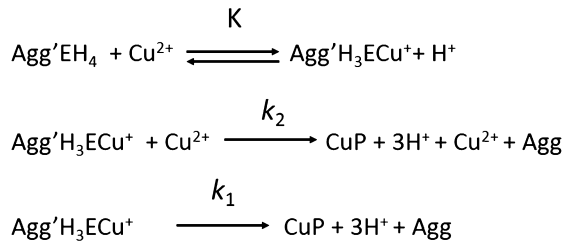

The proposed mechanism assumes the presence of a "reactive" terminal diacid porphyrin $\left(\mathrm{EH}_{4}\right)$ at the end of the rim of the nanoassembly or nanotube, containing $n$ porphyrin units $\left(\mathrm{Agg}^{\prime} \mathrm{EH}_{4}\right)$ (see left side of Scheme 3).

Scheme 3. Formation of the Intermediate Species by Interaction of $\mathrm{Cu}^{2+}$ with Only One of the Nitrogen Atoms of the Protonated Core of a Reactive TPPS 4 Unit at the Rim of the J-Aggregates and Subsequent Insertion of the Metal Ion and Release of the Final CuTPPS 4 Metal Complex and Solvent Molecules

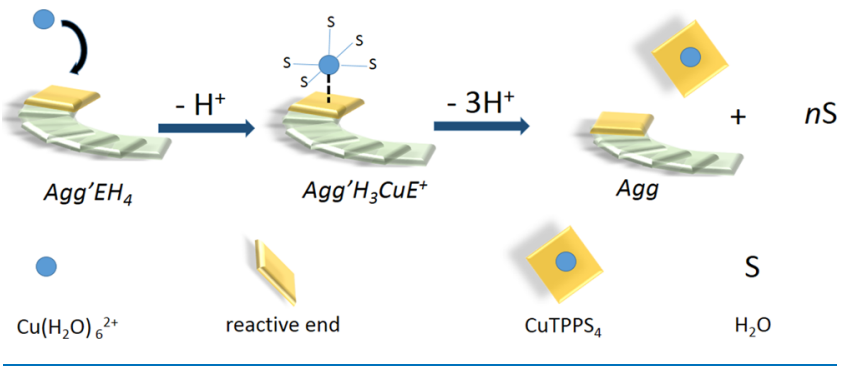

The reactivity of porphyrins within the extended assembly "interior porphyrins" is considered to be negligible because the porphyrin core is completely hindered by the porphyrinporphyrin interactions stabilizing the network. Any involvement of these porphyrins would lead to a fragmentation of the aggregates, with a time-dependent formation of new reactive ends and acceleration of the rates. The linear kinetic traces and RLS experiments have ruled out such a possibility. ${ }^{40}$ The "porphyrin end" is the preferred site of attack for a copper(II) ion leading to the formation of an intermediate species $\left(\mathrm{Agg}^{\prime} \mathrm{H}_{3} \mathrm{ECu}^{+}\right)$, in which the metal interacts with the porphyrin core with a concomitant loss of a proton (equilibrium constant $K)$. Because the porphyrin reactive end is part of the aggregate, only one of the two exposed nitrogen atoms of the porphyrin core is coordinating the copper ion, acting as a monodentate 
ligand $\left(\mathrm{Agg}^{\prime} \mathrm{H}_{3} \mathrm{ECu}^{+}\right.$, Scheme 3). As further support of this point, recall that in reactions involving the metallation of monomeric porphyrins in aqueous solution, a complex dependence of rate on the proton concentration is commonly observed because of the two protonation equilibria involving the macrocycle core. In the present case, the observation of a simple inverse dependence suggests the loss of a single proton. In a successive step, the intermediate species, still embedded in the porphyrin nanoassembly, can undergo a metal ion insertion into the macrocycle core, with the formation of the final square planar copper(II) porphyrin complex, CuP. The release of proton ions in this mechanism is not expected to alter the $\mathrm{pH}$ of the bulk solution, because of the much larger concentration of $\mathrm{H}_{2} \mathrm{SO}_{4}$ (millimolar range) with respect to the porphyrin (micromolar range). Two distinct reaction pathways are proposed: (i) a metal assisted path via $k_{2}$ and (ii) a direct insertion of copper(II) via $k_{1}$. This latter type of mechanism is observed for many porphyrins, ${ }^{51}$ but the participation of a second metal ion (equal or different with respect to the inserted one) has been reported for meso-tetra(pyridyl)porphyrins with di- and trivalent metal ions in aqueous solution. ${ }^{52}$ In both cases, the aggregate, containing $n-1$ units, is eventually released (Agg) and a new porphyrin reactive end will be available again until complete disruption of the nanoassembly (right side of Scheme 3 ). The time independence of the "porphyrin ends" concentration along the process (i.e., the concentration of reactive porphyrin remains small and is continuously replenished during the process) is in line with the observed zero-order kinetics, $k_{0}$, and the overall rate law.

The very small term $\mathrm{A}$ in the fit of the rate constants in Figure $2\left(A=(7.96 \pm 2.52) \times 10^{-11} \mathrm{M} \cdot \mathrm{s}^{-1}\right)$ can be ascribed to statistical errors or to a metal ion independent pathway, in which a very slow dissociation of monomers from the nanoassemblies is responsible for this small contribution. Indeed, under the same experimental conditions, the reactivity of the free diacid porphyrin toward copper(II) is at least an order of magnitude larger, with respect to the porphyrin embedded in the aggregates $\left(t_{1 / 2} \approx 80 \mathrm{~s}\right.$ vs $\left.t_{1 / 2} \approx 1500 \mathrm{~s}\right)$. Activation parameters for the disassembling process have been determined from an Eyring plot giving $\Delta H^{\neq}=(+163 \pm 15) \mathrm{kJ}$. $\mathrm{mol}^{-1}$ and $\Delta S^{\neq}=(+136 \pm 11) \mathrm{J} \cdot \mathrm{K}^{-1}$ (Figure 4 and Table SI 4 ). The large positive value for the activation entropy may be due to the release of the metal derivative $\mathrm{CuP}$ from the nanoassembly to the solution and the loss of the water ligands coordinated to the copper center in the intermediate species,

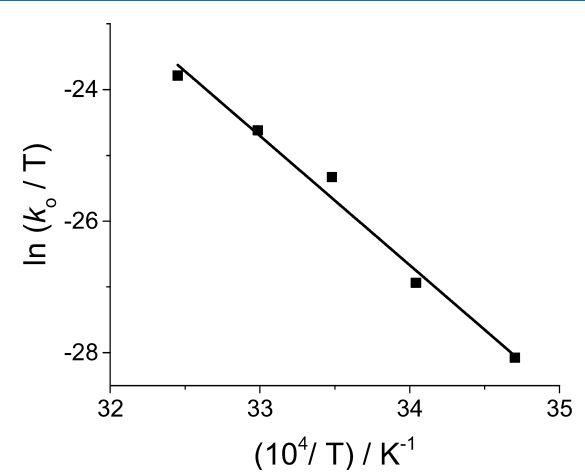

Figure 4. Eyring plot of the observed zeroth-order rate constants for the disassembling process of J-aggregated $\mathrm{TPPS}_{4}$ as induced by copper(II) ions $\left(\left[\mathrm{TPPS}_{4}\right]=3 \mu \mathrm{M},\left[\mathrm{H}_{2} \mathrm{SO}_{4}\right]=0.0016 \mathrm{M},\left[\mathrm{Cu}^{2+}\right]=0.4\right.$ M, I.S. $\left.=3.2 \mathrm{M}\left(\mathrm{NiSO}_{4}\right)\right)$. when the metal enters the porphyrin core (Scheme 3 ). For the sake of comparison, we determined the activation parameters for the copper(II) insertion into the monomeric diacid $\mathrm{TPPS}_{4}$, obtaining $\Delta H^{\neq}=(+143 \pm 6) \mathrm{kJ} \cdot \mathrm{mol}^{-1}$ and again a large positive $\Delta S^{\neq}=(+194 \pm 11) \mathrm{J} \cdot \mathrm{K}^{-1}$ (see Figure SI5 and Table SI5). These values are in line with literature data on the same porphyrin, even at different ionic strengths. ${ }^{46}$ When comparing the activation parameters for the copper(II) insertion in the free monomer and in the aggregate, the observed differences could be related to how the nanoassembly structure induces changes in the way the metal ion approaches the available face of the terminal porphyrin unit. Also, the sulfonate group of the porphyrin preceding the exposed terminal end could be responsible for a change in the interaction of the reactive end with the copper ion.

\section{CONCLUSIONS}

Given the large and burgeoning interest in J-aggregates for many potential applications, such as optoelectronic devices, ${ }^{18}$ optical waveguide, ${ }^{53}$ or nonlinear optics, ${ }^{22}$ a precise understanding of the factors governing their stability and controlling their sizes is very important. Moreover, a detailed knowledge of the kinetics of their disassembly allows controlling the release of porphyrins in a time-dependent way. This mechanism can be conveniently triggered by external stimuli, such as $\mathrm{pH}$ or metal ion concentration changes, making these aggregates as nanoreservoirs of porphyrin units, exploitable, for example, in photodynamic therapy or nanomedicine. ${ }^{54}$ Copper(II) has been chosen in the present study because of its lability, the relative stability of its metal complexes under acidic conditions and its limited redox behavior. However, other metal ions could be used to trigger the assembly/disassembly process of $\mathrm{TPPS}_{4}$ porphyrin, opening the way to a variety of potential stimuli controlled applications.

\section{EXPERIMENTAL SECTION}

The porphyrin 5,10,15,20-tetrakis(4-sulfonatophenyl)porphyrin $\left(\mathrm{TPPS}_{4}\right)$ as the tetrasodium salt was purchased from Frontier Scientific. $\mathrm{CuSO}_{4} \cdot 5 \mathrm{H}_{2} \mathrm{O}, \mathrm{NiSO}_{4}, \mathrm{ZnSO}_{4}$, and sulfuric acid (ACS grade) were obtained from Aldrich Co. and used as received. Milli-Q water was used for preparing all solutions. A concentrated stock solution of $\mathrm{TPPS}_{4}$ was freshly prepared, and the concentration of the stock solution was calculated using $\varepsilon_{412}=5.33 \times 10^{5} \mathrm{M}^{-1} \cdot \mathrm{cm}^{-1}$ at the B-band in neutral aqueous solution of low $(\sim 0)$ ionic strength.

$\mathrm{UV} /$ vis extinction spectra were recorded on an Agilent 8453 diode array and on a Jasco V-550 spectrophotometer using 1 $\mathrm{cm}$ path length quartz cells. Because of the nonmolecular nature of the system under investigation, differences in the kinetic parameters are expected, when different sets of experiments are compared. The strong dependence of kinetics under initial conditions or even on the mixing protocol has been already pointed out in our previous papers. ${ }^{7}$ In the present work, to obtain a better reproducibility of the data, when investigating a particular effect (i.e., copper(II) concentration or $\mathrm{pH}$ ), a complete series of kinetic runs have been performed using the same batch of preformed Jaggregate. To this purpose, a large volume of solution of TPPS $_{4}$ J-aggregate $(10 \mathrm{~mL})$ was prepared using a porphyrin last protocol by adding a known volume of concentrated $\mathrm{TPPS}_{4}$ solution (ca. $200 \mu \mathrm{M}$ ) to a solution containing $\mathrm{NiSO}_{4}$ (or $\mathrm{ZnSO}_{4}$ ) and $\mathrm{H}_{2} \mathrm{SO}_{4}$ at the required concentration, and the 
solution was equilibrated for at least an hour. Kinetic runs were initiated in a plastic cell placed in the thermostated compartment of the instruments by mixing equal volumes of a solution containing $\mathrm{CuSO}_{4}, \mathrm{NiSO}_{4}\left(\right.$ or $\mathrm{ZnSO}_{4}$ ), and $\mathrm{H}_{2} \mathrm{SO}_{4}$ at the required concentration and the solution containing the preformed J-aggregate (in all the experiments I.S. $=3.2 \mathrm{M}$ by addition of $\mathrm{NiSO}_{4}\left(\right.$ or $\left.\mathrm{ZnSO}_{4}\right)$ ).

The zero-order kinetics was analyzed by a linear fit of the extinction data collected at $490 \mathrm{~nm}$ after normalization to unity. The concentration of aggregated monomers at any time has been obtained by subtracting the amount of diacid or metallated porphyrin (determined using literature values of the extinction coefficients) from the initial $\mathrm{TPPS}_{4}$ concentration, obtaining zero-order kinetic constants $\left(\mathrm{M} \cdot \mathrm{s}^{-1}\right)$ as slopes.

\section{ASSOCIATED CONTENT}

\section{S Supporting Information}

The Supporting Information is available free of charge on the ACS Publications website at DOI: 10.1021/acsomega.8b02913.

Dependencies of rate constants on $\left[\mathrm{TPPS}_{4}\right],\left[\mathrm{Cu}^{2+}\right]$, and $\mathrm{pH}$ (I.S. with $\mathrm{ZnSO}_{4}$ ), Eyring plots for the disaggregation in the presence of $\mathrm{ZnSO}_{4}$ and for metallation of $\mathrm{TPPS}_{4}$ with copper(II), and primary kinetic data (PDF)

\section{AUTHOR INFORMATION}

\section{Corresponding Author}

*E-mail: lmonsu@unime.it. Tel: +390906765711.

\section{ORCID}

Maria A. Castriciano: 0000-0002-1514-8820

Luigi Monsù Scolaro: 0000-0002-9742-9190

\section{Author Contributions}

The manuscript was written through contributions of all authors. All authors have given approval to the final version of the manuscript.

\section{Notes}

The authors declare no competing financial interest.

\section{ACKNOWLEDGMENTS}

The authors thank the MIUR (PRIN 2015 project no. 2015XBZ5YA), the CNR "Nanomateriali e nanotecnologie per lo sviluppo sostenibile ed il patrimonio culturale" (CUP: G78B14000100006, 1/2012, grant to R.Z.), the MatISSE" Materiali Innovativi e Sostenibili per la Salute e l'Energia (CUP G77B17000180009, grant to M.T.), and the University of Messina Research \& Mobility 2015 Project (project code RES_AND_MOB_2015_DE_LUCA) for the financial support.

\section{REFERENCES}

(1) Hambright, P. Chemistry of Water Soluble Porphyrins. In The Porphyrin Handbook; Kadish, K. M., Smith, K. M., Guilard, R., Eds.; Academic Press: San Diego, CA, 2000; Vol. 3.

(2) Rao, V. H.; Krishnan, V. Kinetics of Porphyrin Metalation Reactions in Micellar Media. Singlet Emission Studies. Inorg. Chem. 1985, 24, 3538-3541.

(3) Keiser, B. A.; Holt, S. L. Reactions in Detergentless Microemulsions: Incorporation of Copper(Ii) into Meso-Tetraphenylporphine $\left((\mathrm{TPP}) \mathrm{H}_{2}\right)$ in a Water/Oil Microemulsion. Inorg. Chem. 1982, 21, 2323-2327.
(4) Pasternack, R. F.; Gibbs, E. J.; Santucci, R.; Schaertel, S.; Ellinas, P.; Mah, S. C. Influence of DNA on the Rate of Porphyrin Metallation. J. Chem. Soc., Chem. Commun. 1987, 0, 1771-1774.

(5) Fuhrhop, J. H. Porphyrin Assemblies and Their Scaffolds. Langmuir 2014, 30, 1-12.

(6) Pasternack, R. F.; Huber, P. R.; Boyd, P.; Engasser, G.; Francesconi, L.; Gibbs, E.; Fasella, P.; Cerio Venturo, G.; Hinds, L. deC. Aggregation of Meso-Substituted Water-Soluble Porphyrins. J. Am. Chem. Soc. 1972, 94, 4511-4517.

(7) Romeo, A.; Castriciano, M. A.; Occhiuto, I.; Zagami, R.; Pasternack, R. F.; Scolaro, L. M. Kinetic Control of Chirality in Porphyrin J-Aggregates. J. Am. Chem. Soc. 2014, 136, 40-43.

(8) Schwab, A. D.; Smith, D. E.; Rich, C. S.; Young, E. R.; Smith, W. F.; de Paula, J. C. Porphyrin Nanorods. J. Phys. Chem. B 2003, 107, 11339-11345.

(9) Wang, Z.; Li, Z.; Medforth, C. J.; Shelnutt, J. A. Self-Assembly and Self-Metallization of Porphyrin Nanosheets. J. Am. Chem. Soc. 2007, 129, 2440-2441.

(10) White, W. I. Aggregation of Porphyrins and Metalloporphyrins. In The Porphyrins, Dolphin, D., Ed. Academic Press: New York, 1978; Vol. 5, pp 303-339.

(11) Maiti, N. C.; Mazumdar, S.; Periasamy, N. J- and H-Aggregates of Porphyrins with Surfactants: Fluorescence, Stopped Flow and Electron Microscopy Studies. J. Porphyrins Phthalocyanines 1998, 2, 369-376.

(12) McRae, E. G.; Kasha, M. Enhancement of Phosphorescence Ability upon Aggregation of Dye Molecules. J. Chem. Phys. 1958, 28, 721-722.

(13) Pasternack, R. F.; Fleming, C.; Herring, S.; Collings, P. J.; dePaula, J.; DeCastro, G.; Gibbs, E. J. Aggregation Kinetics of Extended Porphyrin and Cyanine Dye Assemblies. Biophys. J. 2000, 79, 550-60.

(14) Purrello, R.; Scolaro, L. M.; Bellacchio, E.; Gurrieri, S.; Romeo, A. Chiral H- and J-Type Aggregates of meso-Tetrakis(4Sulfonatophenyl)Porphine on $\alpha$-Helical Polyglutamic Acid Induced by Cationic Porphyrins. Inorg. Chem. 1998, 37, 3647-3648.

(15) Akins, D. L.; Zhu, H. R.; Guo, C. Absorption and RamanScattering by Aggregated meso-Tetrakis(p-Sulfonatophenyl)Porphine. J. Phys. Chem. 1994, 98, 3612-3618.

(16) Collings, P. J.; Gibbs, E. J.; Starr, T. E.; Vafek, O.; Yee, C.; Pomerance, L. A.; Pasternack, R. F. Resonance Light Scattering and Its Application in Determining the Size, Shape, and Aggregation Number for Supramolecular Assemblies of Chromophores. J. Phys. Chem. B 1999, 103, 8474-8481.

(17) Collini, E.; Ferrante, C.; Bozio, R. Strong Enhancement of the Two-Photon Absorption of Tetrakis(4-sulfonatophenyl)porphyrin Diacid in Water Upon Aggregation. J. Phys. Chem. B 2005, 109, 2-5.

(18) Collini, E.; Ferrante, C.; Bozio, R.; Lodi, A.; Ponterini, G. Large Third-Order Nonlinear Optical Response of Porphyrin J-Aggregates Oriented in Self-Assembled Thin Films. J. Mater. Chem. 2006, 16, $1573-1578$.

(19) Maiti, N. C.; Ravikanth, M.; Mazumdar, S.; Periasamy, N. Fluorescence Dynamics of Noncovalently Linked Porphyrin Dimers, and Aggregates. J. Phys. Chem. B 1995, 99, 17192-17197.

(20) Monsù Scolaro, L.; Romeo, A.; Castriciano, M. A.; Micali, N. Unusual Optical Properties of Porphyrin Fractal J-Aggregates. Chem. Commun. 2005, 0, 3018-3020.

(21) Ribó, J. M.; Rubires, R.; El-Hachemi, Z.; Farrera, J. A.; Campos, L.; Pakhomov, G. L.; Vendrell, M. Self-Assembly to Ordered Films of the Homoassociate Solutions of the Tetrasodium Salt of 5,10,15,20Tetrakis(4-Sulfonatophenyl) Porphyrin Dihydrochloride. Mater. Sci. Eng.: C 2000, 11, 107-115.

(22) Schwab, A. D.; Smith, D. E.; Bond-Watts, B.; Johnston, D. E.; Hone, J.; Johnson, A. T.; de Paula, J. C.; Smith, W. F. Photoconductivity of Self-Assembled Porphyrin Nanorods. Nano Lett. 2004, 4, 1261-1265.

(23) Castriciano, M. A.; Romeo, A.; Villari, V.; Micali, N.; Scolaro, L. M. Structural Rearrangements in 5,10,15,20-Tetrakis(4- 
Sulfonatophenyl)Porphyrin J-Aggregates under Strongly Acidic Conditions. J. Phys. Chem. B 2003, 107, 8765-8771.

(24) Micali, N.; Villari, V.; Castriciano, M. A.; Romeo, A.; Scolaro, L. M. From Fractal to Nanorod Porphyrin J-Aggregates. ConcentrationInduced Tuning of the Aggregate Size. J. Phys. Chem. B 2006, 110, $8289-8295$.

(25) Occhiuto, I. G.; Zagami, R.; Trapani, M.; Bolzonello, L.; Romeo, A.; Castriciano, M. A.; Collini, E.; Monsù Scolaro, L. The Role of Counter-Anions in the Kinetics and Chirality of Porphyrin JAggregates. Chem. Commun. 2016, 52, 11520-11523.

(26) Short, J. M.; Berriman, J. A.; Kubel, C.; El-Hachemi, Z.; Naubron, J. V.; Balaban, T. S. Electron Cryo-Microscopy of TPPS4. $2 \mathrm{HCl}$ Tubes Reveals a Helical Organisation Explaining the Origin of Their Chirality. ChemPhysChem 2013, 14, 3209-3214.

(27) El-Hachemi, Z.; Balaban, T. S.; Campos, J. L.; Cespedes, S.; Crusats, J.; Escudero, C.; Kamma-Lorger, C. S.; Llorens, J.; Malfois, M.; Mitchell, G. R.; Tojeira, A. P.; Ribó, J. M. Effect of Hydrodynamic Forces on meso-(4-Sulfonatophenyl)-Substituted Porphyrin J-Aggregate Nanoparticles: Elasticity, Plasticity and Breaking. Chem. - Eur. J. 2016, 22, 9740-9749.

(28) Friesen, B. A.; Nishida, K. R. A.; McHale, J. L.; Mazur, U. New Nanoscale Insights into the Internal Structure of Tetrakis(4sulfonatophenyl) Porphyrin Nanorods. J. Phys. Chem. C 2009, 113, $1709-1718$.

(29) Gandini, S. C. M.; Gelamo, E. L.; Itri, R.; Tabak, M. Small Angle X-Ray Scattering Study of Meso-Tetrakis (4-Sulfonatophenyl) Porphyrin in Aqueous Solution: A Self-Aggregation Model. Biophys. J. 2003, 85, 1259-1268.

(30) Micali, N.; Mallamace, F.; Romeo, A.; Purrello, R.; Scolaro, L. M. Mesoscopic Structure of meso-Tetrakis(4-Sulfonatophenyl)Porphine J-Aggregates. J. Phys. Chem. B 2000, 104, 5897-5904.

(31) Castriciano, M. A.; Romeo, A.; Villari, V.; Micali, N.; Scolaro, L. M. Nanosized Porphyrin J-Aggregates in Water/AOT/Decane Microemulsions. J. Phys. Chem. B 2004, 108, 9054-9059.

(32) Castriciano, M. A.; Romeo, A.; Zagami, R.; Micali, N.; Scolaro, L. M. Kinetic Effects of Tartaric Acid on the Growth of Chiral JAggregates of Tetrakis(4-Sulfonatophenyl)Porphyrin. Chem. Commun. 2012, 48, 4872-4874.

(33) Gaeta, M.; Raciti, D.; Randazzo, R.; Gangemi, C. M. A.; Raudino, A.; D’Urso, A.; Fragalà, M. E.; Purrello, R. Chirality Enhancement of Porphyrin Supramolecular Assembly Driven by a Template Preorganization Effect. Angew. Chem., Int. Ed. 2018, 57, 10656-10660.

(34) Romeo, A.; Castriciano, M. A.; Scolaro, L. M. Spectroscopic and Kinetic Investigations on Porphyrin J-Aggregates Induced by Polyamines. J. Porphyrins Phthalocyanines 2010, 14, 713-721.

(35) Romeo, A.; Castriciano, M. A.; Zagami, R.; Pollicino, G.; Monsù Scolaro, L.; Pasternack, R. F. Effect of Zinc Cations on the Kinetics for Supramolecular Assembling and the Chirality of Porphyrin J-Aggregates. Chem. Sci. 2017, 8, 961-967.

(36) Zagami, R.; Romeo, A.; Castriciano, M. A.; Monsù Scolaro, L. Inverse Kinetic and Equilibrium Isotopic Effects on Self-Assembly and Supramolecular Chirality of Porphyrin J-Aggregates. Chem. - Eur. J. 2017, 23, 70-74.

(37) Pasternack, R. F.; Gibbs, E. J.; Collings, P. J.; dePaula, J. C.; Turzo, L. C.; Terracina, A. A Nonconventional Approach to Supramolecular Formation Dynamics. The Kinetics of Assembly of DNA-Bound Porphyrins. J. Am. Chem. Soc. 1998, 120, 5873-5878.

(38) Li, Y.; Steer, R. P. Kinetics of Disaggregation of a Non-Covalent Zinc Tetraphenylporphyrin Dimer in Solution. Chem. Phys. Lett. 2003, 373, 94-99.

(39) Mohr, A.; Talbiersky, P.; Korth, H.-G.; Sustmann, R.; Boese, R.; Bläser, D.; Rehage, H. A New Pyrene-Based Fluorescent Probe for the Determination of Critical Micelle Concentrations. J. Phys. Chem. B 2007, 111, 12985-12992.

(40) Occhiuto, I.; De Luca, G.; Trapani, M.; Scolaro, L. M.; Pasternack, R. F. Peripheral Stepwise Degradation of a Porphyrin JAggregate. Inorg. Chem. 2012, 51, 10074-10076.
(41) Pasternack, R. F.; Gibbs, E. J.; Bruzewicz, D.; Stewart, D.; Engstrom, K. S. Kinetics of Disassembly of a DNA-Bound Porphyrin Supramolecular Array. J. Am. Chem. Soc. 2002, 124, 3533-3539.

(42) Wu, J.-J.; Ma, H.-L.; Mao, H.-S.; Wang, Y.; Jin, W.-J. Investigation on Disassociation of Porphyrin J-Aggregates Induced by $\beta$-Cyclodextrins Using Absorption and Fluorescence Spectroscopy. J. Photochem. Photobiol., A 2005, 173, 296-300.

(43) Zagami, R.; Castriciano, M. A.; Romeo, A.; Trapani, M.; Pedicini, R.; Monsù Scolaro, L. Tuning Supramolecular Chirality in Nano and Mesoscopic Porphyrin J-Aggregates. Dyes Pigm. 2017, 142, 255-261.

(44) Zhai, D.; Xu, W.; Zhang, L.; Chang, Y.-T. The Role of "Disaggregation" in Optical Probe Development. Chem. Soc. Rev. 2014, 43, 2402-2411.

(45) Lavallee, D. K. Kinetics and Mechanisms of Metalloporphyrin Reactions. Coord. Chem. Rev. 1985, 61, 55-96.

(46) Cheung, S. K.; Dixon, F. L.; Fleischer, E. B.; Jeter, D. Y.; Krishnamurthy, M. Kinetic Studies of the Formation, Acid-Catalyzed Solvolysis, and Cupric Ion Displacement of a Zinc Porphyrin in Aqueous Solutions. Bioinorg. Chem. 1973, 2, 281-294.

(47) Hambright, P. The Coordination Chemistry of Metalloporphyrins. Coord. Chem. Rev. 1971, 6, 247-268.

(48) Kemnitz, K.; Sakaguchi, T. Water-soluble porphyrin monomer-dimer systems: fluorescence dynamics and thermodynamic properties. Chem. Phys. Lett. 1992, 196, 497-503.

(49) Cotton, F. A.; Wilkinson, G.; Murillo, C. A.; Bochmann, M. Advanced Inorganic Chemistry, 6th ed.; John Wiley \& Sons: New York, 1999.

(50) Weaver, J. A.; Hambright, P. Kinetics of the Incorporation of Copper(II) into a Water-Soluble Porphyrin. Inorg. Chem. 1969, 8, $167-168$.

(51) Schneider, W. Kinetics and Mechanism of Metalloporphyrin Formation. Struct. Bonding (Berlin, Ger.) 1975, 23, 123.

(52) Fleischer, E. B.; Choi, E. I.; Hambright, P.; Stone, A. Porphyrin Studies: Kinetics of Metalloporphyrin Formation. Inorg. Chem. 1964, 3, 1284-1287.

(53) Kim, T.; Ham, S.; Lee, S. H.; Hong, Y.; Kim, D. Enhancement of Exciton Transport in Porphyrin Aggregate Nanostructures by Controlling the Hierarchical Self-Assembly. Nanoscale 2018, 10, 16438-16446.

(54) Watanabe, K.; Kano, K. Time-Dependent Enzyme Activity Dominated by Dissociation of J-Aggregates Bound to Protein Surface. Bioconjugate Chem. 2010, 21, 2332-2338. 